\title{
Birleştirilmiş Elektromekanik Sonlu Elemanlar Yöntemi ile Güç Transformatörünün Termal Alan Analizi
}

\author{
Yıldırım ÖZÜPAK ${ }^{1 *} \mathbb{D}$, Mehmet Salih MAMİŞ$^{2}$ \\ ${ }^{1}$ Dicle Üniversitesi, Silvan Meslek Yüksekokulu, Elektrik ve Enerji Programı, Diyarbakır \\ ${ }^{2}$ İnönü Üniversitesi, Mühendislik Fakültesi, Elektrik Elektronik Mühendisliği, Malatya \\ Geliş / Received: 17/01/2019, Kabul / Accepted: 13/05/2019
}

\begin{abstract}
Özet
Transformatör tasarımına başlamadan önce, sıcaklık dağılımının ve termal sınırların bilinmesi doğru bir tasarım için büyük önem teşkil etmektedir. İzin verilen termal sınırların üzerindeki sıcaklık, transformatör bileşenlerinde ciddi hasara neden olabilmektedir. Bu çalışmada, termal alan analizi için bir model sunulmuştur. Bu sayede, transformatörün aktif kısımlarında meydana gelen ısıdan ortamın sıcaklığına kadar tüm koşullar esas alınarak birleştirilmiş elektromekanik Sonlu Elemanlar Yöntemi (SEY) tekniğine dayanan ANSYS@Maxwell ve ANSYS@Mechanical birleşimi simülasyon yazılımı ile üç fazlı bir transformatörün sıcaklık dağılımı ve termal

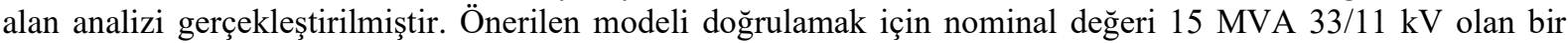
transformatör seçilmiştir. Simülasyondan elde edilen değerler deneysel değerlerle karşılaştırılarak model ve sonuçlar doğrulanmıştır. Tasarlanan model sayesinde, transformatörün nüvesinde ve sargılarında meydana gelen sıcaklık dağılımı ve transformatörün sıcaklığı ölçülemeyen bölgelerindeki spesifik noktaların sıcaklığı belirlenmiştir.
\end{abstract}

Anahtar Kelimeler: Termal Analiz, Transformatör, SEY, Maxwell-3D.

\section{Thermal Analysis of Power Transformer by Combined Electromechanical Finite Element Method}

\begin{abstract}
Before starting the transformer design, knowing the temperature distribution and the thermal limits are of great importance for a correct design. The temperature above the permissible thermal limits may cause serious damage to the transformer components. In this study, a model for thermal field analysis is presented. In this way, temperature distribution and thermal field analysis of a three-phase transformer were performed by ANSYS@Maxwell and ANSYS@Mechanical combination simulation software based on the combined electromechanical Finite Element Method (FEM) technique based on all conditions ranging from the heat occurring in the active parts of the transformer to the temperature of the environment. To verify the proposed model, a transformer with a nominal value of 15 MVA of $33 / 11 \mathrm{kV}$ was selected. The values obtained from the simulation were compared with the experimental values and the models and results were confirmed. Thanks to the designed model, the temperature distribution in the core and the windings of the transformer and the temperature of the specific points in the undetectable areas of the transformer temperature were determined.
\end{abstract}

Keywords: Thermal Analysis, Transformer, FEM, Maxwell-3D

\section{Giriş}

Transformatördeki asıl kayıplar, nüve ve sargılarda ısıya dönüşen, indüklenen

$\mathrm{Bu}$ nedenle, transformatörün aktif kısımlarını aşırı ısınmalara karşı korumak manyetik alanlardan meydana gelmektedir. $\mathrm{Bu}$ kayıplar, transformatörlerde meydana gelen ısının temel kaynağıdır.

ve yalıtım malzemesinin bozulmasın önlemek için sıcaklığın etkili bir şekilde 
düşürülmesi

gerekmektedir.

Transformatörün maksimum sıcaklığı, transformatörün tasarımı, ortam koşulları, çalışma sırasındaki yük koşulu, soğutma sisteminin tasarımı ve soğutma yağının özellikleri gibi önemli etkenlere bağlidır (Hjalmars, 2012). Transformatör tasarımındaki kritik faktör, transformatörün maksimum sicaklik derecesidir. Sicaklık artışı için sınırlama aralığı Uluslararası Standartta açıkça belirtilmiştir (Yugendrao, 2016). Transformatörün her bir parçasının sıcaklık dağılımı, Sonlu Elemanlar Yöntemi (SEY) ve sonlu fark gibi çeşitli sayısal tekniklere dayanan programlarla termal analizler yapilarak tahmin edilebilir. Sayısal yöntemler, termal teste ve deneysel formüllere alternatif ve uyumlu bir hesaplama olarak kabul edilmiştir (Kardag, 2012). Sonlu Elemanlar Yöntemine dayanan yazılım paketi kullanılarak, karmaşık geometrilerin simülasyonu ve analizleri gerçekleştirilebilmektedir. $\mathrm{Bu}$ şekilde elde edilen yağ ve sargı sıcaklık değerlerinin deneysel yöntemlerle elde edilen sıcaklık değerlerine çok yakın olduğu belirlenmiştir. Elektromanyetik alanların termal alanlar üzerindeki etkisini incelemek bir algoritma uygulanmıştır (Orozs vd, 2016). Daha önceki diğer araştırmalarda yağ soğutmalı dağıtım trafosu için elektromanyetik alanın termal alan üzerindeki etkisi konularında incelemeler yapılmıştır (Myint ve Oo, 2016). Transformatör tasarımının birinci aşaması, varsayımsal bir işlem olarak sıcaklık dağılımını tahmin etmektir. Güç dağıtımında önemli ve pahalı cihazlara zarar verebilen veya düşük performansa neden olabilen sicaklık derecesinin tasarım sinırından daha fazla olmaması gerekmektedir (Chen ve Pillay, 2002). Bu nedenle, bu temel verilerin üretim sürecinden önce elde edilmesi için termal modeller formüle edilmelidir.

$\mathrm{Bu}$ çalışmada, transformatördeki sıcaklık dağılımını elde etmek için bir termal model önerilmiştir. Önerilen model, SEY'e dayanarak alan analizi yapan ve enerji denklemlerini çözen ANSYS@Maxwell yazılımı ile formüle edilmiştir. Aktif kısımlardaki (nüve ve sarılar) elektriksel kayıplar, üretici firma tarafından pratik olarak elde edilmiştir. $\mathrm{Bu}$ değerler aynı zamanda transformatörün özellikleri ve boyutları kullanılarak da hesaplanmıştır. $\mathrm{Bu}$ kayıplar termal analiz prosedüründe üretilen is1 olarak nitelendirilmiștir. Önerilen modeli kullanmaktan beklenen muhtemel sonuç, transformatörün temel bileşenlerinin sıcaklık dağılımını belirleyerek transformatördeki en sicak bölgeyi bulmaktır. Son olarak, "15 MVA 33/11 kV çekirdek tipi, kuru tip" transformatörün termal alanı 3D olarak modellenerek Sonlu Elemanlar Yöntemi ile analiz edilmiştir. Elde edilen sonuçlar, üretici tarafından gerçekleştirilen pratik test sonuçları ile karşılaştırılmıştır.

\section{Termal Alanın Matematiksel Modeli}

Dağıtım transformatörünün termal alanı, Sonlu Elemanlar Yöntemine dayanan ANSYS@Maxwell yazılımı ile enerji denklemleri sayısal olarak çözülerek elde edilmiştir. $\mathrm{Bu}$ nedenle, önerilen model tasarlandığında, sonlu elemanların gereksinimleri göz önünde bulundurulmuştur. Dağıtım transformatöründe 1S1, alternatif akım davranışının bir sonucu olarak ortaya çıkan elektromotor kuvvetinin elektriksel dirençte 
meydana getirdiği 1sıdır. Toplam kayıplar (nüve ve bakır kayıpları), termal alan analizi sırasında spesifik parçalarda üretilen 1S1 olarak daha sonra kullanılmak üzere, üretici firma tarafindan nüve ve sargilarda pratik olarak ölçülmüştür. Önerilen model, bu ölçümler baz alınarak tasarlanmış ve analiz edilmiştir. Dağıtım trafosunun bileşenleri aracılığıyla 1s1 transferi sürecinde aşağıdaki adımlar takip edilmektedir (Madžarević vd, 2011). Nüve ve sargilarda meydana gelen 1sı, nüvenin dış yüzeyine ve iletim modlarından sargılara ulaşana kadar kirli malzemeden geçirilir. İletim modundaki yönetim denklemi, aşağıdaki gibi ifade edilen Fourier yasasıdır:

$q=-k \nabla T\left(W / m^{2}\right)$

$\nabla T$ 1S1 akış yönünde sıcaklığın bir mesafedeki oran değişimi, $\mathrm{K}$ materyalin termal geçirgenliği.

Elektromanyetik ve termal alanların kaynakları, transformatör sargıları boyunca akan akımlardır, yani iletkenler aracılığıyla akan akımın sonucu olarak ortaya çıkan joule kayıplarıdır. Bir termal alan aşağıdaki denklemle açıklanmaktadır:

$\nabla(\lambda \nabla \mathrm{T})-\rho c \frac{\partial T}{\partial t}+q_{v}=0$

Bu denklem non-steady state 1sı transferinin diferansiyel denklemini temsil eder. Burada:

T - zamana ve ortama bağlı sicaklık dağılımının fonksiyonu $\left[{ }^{\circ} \mathrm{C}\right]$

c - spesifik 1sı kapasitesi [J/kg.K]

$\rho$ - spesifik materyal yoüunluğu $\left[\mathrm{kg} / \mathrm{m}^{3}\right]$ $\lambda$ - termal iletkenlik sabiti $[W / m . K]$

$q_{v}$ - Gözlenen noktada muhtemel 1s1 kaynağının 1sı üretimi [J]

$t$ - time [s],

Yukarıdakiler ortam ve sicaklık fonksiyonlarıdır.

İletken, nüve, yağ ve ortam havası yüzeyleri arasındaki 1sı değişimi aşağıda denklem 1 'de verilmiştir:

$-\lambda \frac{\partial T}{\partial t}=a\left(T_{p}-T_{f}\right)$

Diferansiyel denklemlerin verilen başlangıç ve son koşullarla çözümü için sonlu elemanlar yöntemi (SEY) kullanılmıştır. SEY yaklaşık bir çözüm sunmaktadır. Bu metodu uygulayarak, 1sı transferinin kısmi diferansiyel denklemini çözme problemi, eşzamanlı lineer denklemler sisteminin çözümüne indirgenmektedir. Sorunun çözüldüğü bölge, sinırlı sayıda unsura bölünür. Eleman düğümlerinin sıcaklıkları çözüm olarak elde edilirken, elemanların içerisindeki sıcaklıklar eleman düğümlerinin değerleri kullanılarak yaklaşık olarak hesaplanmaktadır.

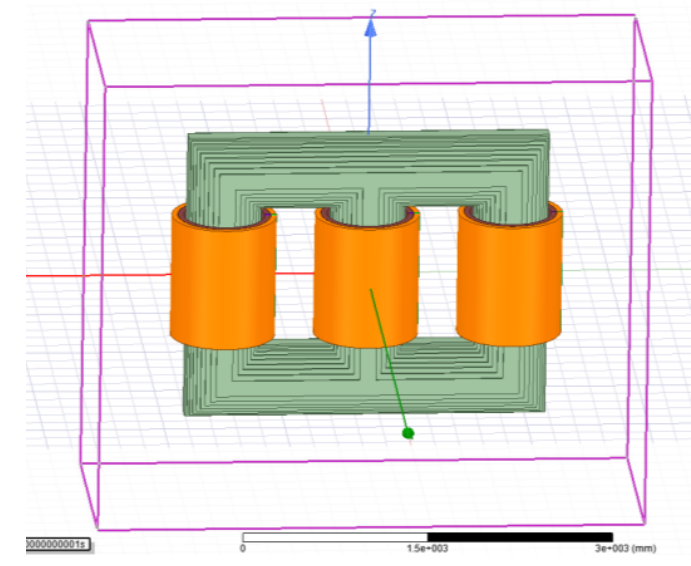

Şekil 1. Dağıtım trafosunun şeması 
Is1 transferinin radyasyon modu, sicaklik farkının bir sonucu olarak, transformatör bileşenleri ve ortam arasında gerçekleşmektedir. Ancak, transformatör bileşenleri düşük emisyona sahip malzemelerden üretilmekte ve radyasyon etkisi çok az olduğu için göz ardı edilmektedir. $\mathrm{Bu}$ durum sonuçların doğruluğunda çok az bir etkiye sahip olmaktadir. Termal modellemenin geliştirilesi sürecinde ve transformatörün termal alan simülasyonunu geliştirmek için, birçok varsayım dikkate alınmıştır:

Simetriye bağlı olarak, transformatör paralel düzlemde bir yapı olarak ele alınabilir. $\mathrm{Bu}$ nedenle, Sonlu Elemanlar Yöntemi kullanılarak çözüldüğünde, kabul edilen doğrulukla iki boyutlu olarak (bir düzlemde) simüle edilebilir.

> Ortam sıcaklığının, günlük ortalama en yüksek değeri dikkate alınır.

> Transformatör malzemelerinin termal özelliklerinin, sicaklık artışından önemli ölçüde etkilenen yalıtım yağı özellikleri hariç, sicaklıkları sabit kabul edilir.

- Aktif materyallerin içinde meydana gelen 1s1 birim hacimde ve birim zamanda düzgün bir şekilde dağitılır.

> Dielektrik izolasyon kayıpları ihmal edilir, çünkü bakır ve demirin neden olduğu kayıplara oranla bu kayıplar çok azdır.

$>$ Konveksiyon modu ile 1s1 transfer oranı doğal bir konveksiyon olarak kabul edilir.

Transformatörün aktif kısımlarının iki boyutlu denklem formundaki enerji dengesi, aşağıdaki gibi kararlı bir durum koşulu ile formüle edilebilir:

$$
\dot{q} V=\frac{d}{d x}\left(k A \frac{d T}{d x}\right)+\frac{d}{d y}\left(k A \frac{d T}{d y}\right)
$$

Çekirdek ve bobin malzemelerinin içindeki herhangi bir noktada meydana gelen isının düzgün dağılımı aşağıdaki gibi hesaplanmaktadır:

$$
\begin{aligned}
& \dot{q}_{\text {core }}=\frac{P_{l, \text { core }}}{V_{\text {core }}} \\
& \dot{q}_{L . V .}=\frac{P_{l, L . V .}}{V_{H . V .}}\left(\mathrm{W} / \mathrm{m}^{3}\right) \\
& \dot{q}_{H . V .}=\frac{P_{l, H . V .}}{V_{L . V .}}\left(\mathrm{W} / \mathrm{m}^{3}\right)
\end{aligned}
$$

Aktif parçaların diş yüzeyinde (yalıtım yağıyla etkileşen yüzeyler), enerji dengesi aşağıdaki gibi uygulanır:

$-k A \frac{d T}{d x}-k A \frac{d T}{d y}=h\left(T-T_{B}\right)$

$T_{B}:$ Kütle sıcaklı̆ $1,{ }^{\circ} \mathrm{C}$

h: katman katsayısı, $\left(W / m^{2},{ }^{\circ} \mathrm{C}\right)$

\section{Transformatörün Modellenmesi}

Transformatörün simülasyon ortamında modellenmesi için, gerçek bir transformatör modeli ve trafo geometrinin detayları kullanılmıştır.

Bu çalışmada 15 MVA 33/11 kV, kuru tip üç fazlı bir trafo incelenmiştir. Tablo 1'de seçilen transformatörün boyutları ve özellikleri sunulmuştur. 
Tablo 1. Trafoya ait tasarım verileri

\begin{tabular}{|c|c|}
\hline Parametre & Değer \\
\hline Görünür Güç & $15 \mathrm{MVA}$ \\
\hline Frekans & $50 \mathrm{~Hz}$ \\
\hline YG & $33.000 \mathrm{~V}$ \\
\hline AG & $11.000 \mathrm{~V}$ \\
\hline Nüve Kaybı & $12.500 \mathrm{~W}$ \\
\hline Bakır Kaybı & $97.000 \mathrm{~W}$ \\
\hline YG Sargı Direnci & $1.7 \Omega$ \\
\hline AG Sarg1 Direnci & $40 \mathrm{~m} \Omega$ \\
\hline Uk & $11 \%$ \\
\hline Io & $\% 0.44$ \\
\hline YG Bağlantı & Delta \\
\hline AG Bağlantı & Y1ldız \\
\hline YG Spir Sayısı & 135 \\
\hline AG Spir Sayısı & 665 \\
\hline YG Faz Akımı & $784 \mathrm{~A}$ \\
\hline AG Faz Akımı & $156 \mathrm{~A}$ \\
\hline Akım Yoğunluğu & $1.8 \mathrm{~A} / \mathrm{m} 2$ \\
\hline
\end{tabular}

Transformatörün 3D/2D modelinin simülasyonu için ticari bir yazılım ve simülasyon programı olan ANSYS@Maxwell_ve ANSYS@Mechanical_programlarının birleşimi kullanılmıştır. Transformatörün modellenmesi için temel noktalar kullanılmış, daha sonra bu noktalar çizgiler oluşturularak birbirine bağlanmıştır. Ardından tüm ana parçaların gerçek boyutlarına bağlı olarak analiz için alanlar oluşturulmuştur.

ANSYS yazılım paketi Sonlu Elemanlar Yöntemine dayanmaktadır. Yani, tüm model veya çözüm bölgesi, alt bölümlere veya öğelere ayrıştırılarak yaklaşık bir çözüm elde etmek için öğeler düğümlerle birbirlerine bağlanarak çözüm gerçekleştirilmektedir. $\mathrm{Bu}$ nedenle, elemanların düzeni, türü, boyutu ve sayısı belirlenmelidir. Mesh'in oluşturulabilmesi için eleman tipi ve tüm seçilmiş elemanlara ait malzemelerin özellikleri tanımlanmalıdır. Üretici firmadan temin edilen termal özellikler program ortamında tanımlanmış ve Tablo 2'de sunulmuştur.

Tablo 2. Transformatörün materyallerinin özellikleri

\begin{tabular}{|l|l|l|l|}
\hline & $\begin{array}{l}\text { Yoğunlu } \\
\mathbf{k}\end{array}$ & $\begin{array}{l}\text { Isotropic } \\
\text { termal } \\
\text { iletkenlik }\end{array}$ & $\begin{array}{l}\text { Spesifik } \\
\text { sicaklık }\end{array}$ \\
\hline $\begin{array}{l}\text { Sargla } \\
\text { r }\end{array}$ & $\begin{array}{l}8933 \\
\mathrm{~kg} / \mathrm{m}^{3}\end{array}$ & $\begin{array}{l}400 \\
\mathrm{~W} / \mathrm{m}^{2 \circ} \mathrm{C}\end{array}$ & $\begin{array}{l}385 \\
\mathrm{j} / \mathrm{kg}^{2 \circ} \mathrm{C}\end{array}$ \\
\hline Nüve & $\begin{array}{l}7650 \\
\mathrm{~kg} / \mathrm{m}^{3}\end{array}$ & $\begin{array}{l}5 \\
\mathrm{~W} / \mathrm{m}^{2 \circ} \mathrm{C}\end{array}$ \\
\hline $\begin{array}{l}\text { İzolasy } \\
\text { on }\end{array}$ & & $\begin{array}{l}4.5 \\
\mathrm{~W} / \mathrm{m}^{2 \circ} \mathrm{C}\end{array}$ & \\
\hline
\end{tabular}

Modelin tasarlanmasındaki bir sonraki adım ise, transformatör için uygun bir mesh oluşturulmasıdır. Mesh gerçekleştirilirken iki nokta dikkate alınmalıdır. Transformatörün boyutları ve şekilleri için uygun olan yeterli sayida ve uygun eleman şekli mevcut olmalıdır. Transformatörün tüm bileşenleri için oluşturulan mesh, farklı şekillerde düğüm ve elemandan meydana gelmektedir. Trafonun geometrisi ve oluşturulan mesh Şekil 2'de sunulmuştur.

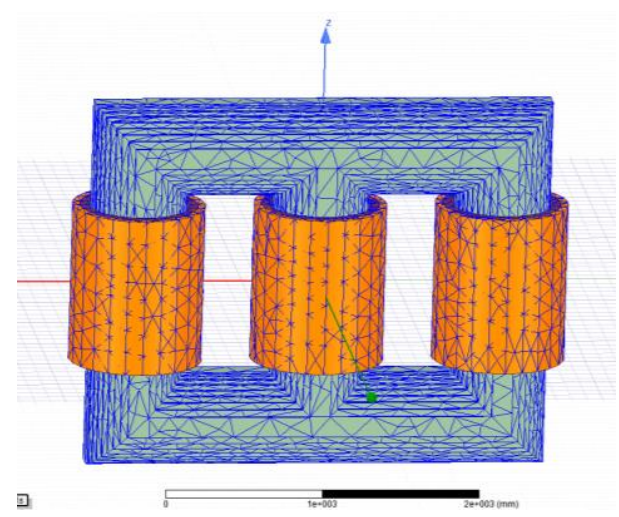

Şekil 2. Üç fazlı transformatör için mesh 
Modelin çözüm için hazırlanmasındaki son adım ise, ısı transfer sürecini bileşenleriyle test etmek için transformatördeki sınır koşulları belirlenmelidir. Nüve ve sargılardaki kayıplar açığa çıkan ısı olarak tanımlanmıştır. Transformatörün elektriksel kayıpları, 1S1 kayıplarının miktarı olarak pratikte ölçülmüştür. Tablo 3'te transformatörün kayıpları gösterilmiştir.

Tablo 3. Trafo bileşenlerinde oluşan isının ölçülen değerleri

\begin{tabular}{|l|l|l|}
\hline & $\begin{array}{l}\text { Bakır } \\
\text { kayıpları }\end{array}$ & $\begin{array}{l}\text { Nüve } \\
\text { kaybı }\end{array}$ \\
\hline $\begin{array}{l}\text { Kayıplar } \\
\text { (kW) }\end{array}$ & 97 & 12.5 \\
\hline
\end{tabular}

İletim sınırı, sargılar ve nüve arasında uygulanır. İletim için sınır koşullarında istenen termal özellik, malzemelerin termal iletkenlik katsayılarıdır. $\mathrm{Bu}$ değerler tablo 2'de belirtilmiştir.

\section{Simülasyon ve Sonuçları}

SEY kullanılarak trafodaki 1S1 transfer yolunu görmek için, oluşan isıların değerleri ve konumları, transformatörün geometrisi, transformatör bileşenleri için malzemenin termal özellikleri ve uygun mesh seçilmesi gibi önemli adımlar belirlenmiştir. Daha sonra, önerilen 1S1 modelinin yardımıyla, trafo yapısının tüm bileşenlerinde sıcaklık dağılımlarını 2D/3D elde etmek için enerji denklemleri çözülmüştür. Transformatörün birer bileşeni olan, Nüve, AG sargısı ve YG sargıSı sıcaklık dağılımlarının ayrıntıları 2D ve $3 \mathrm{D}$ olarak aşağıdaki Şekillerde sunulmuştur.

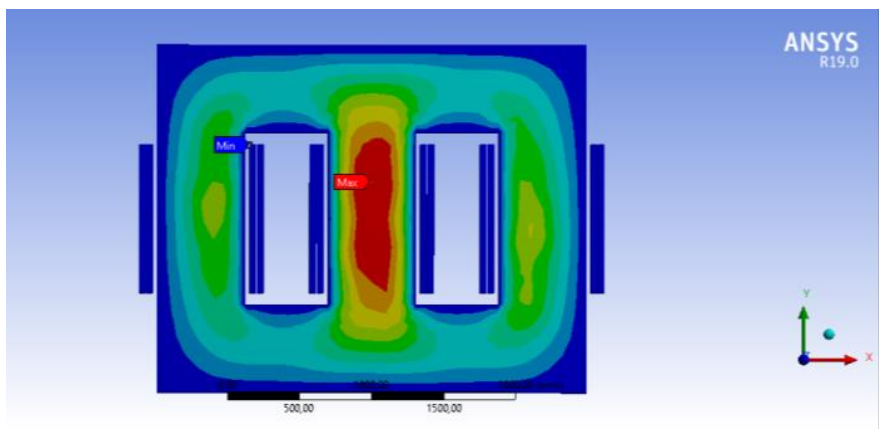

Şekil 4. Trafonun 2D sıcaklık dağılımı

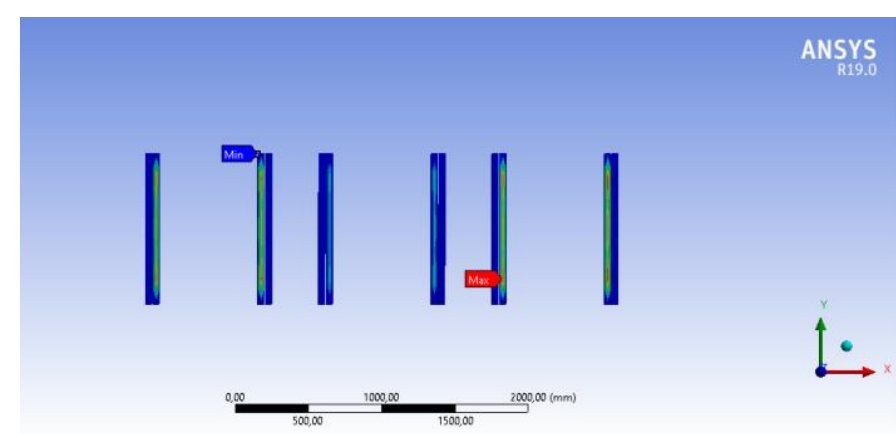

Şekil 5. Sargıların 2D sıcaklık dağılımı

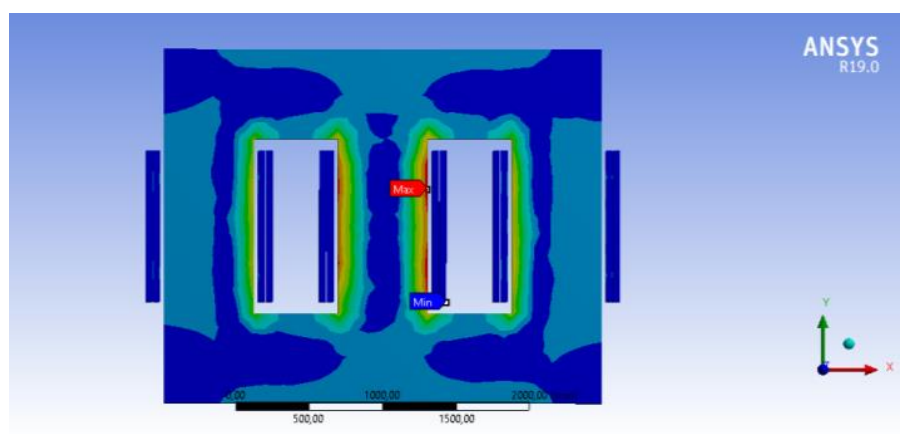

Şekil 6. transformatörün 2D 1sı akış dağılımı

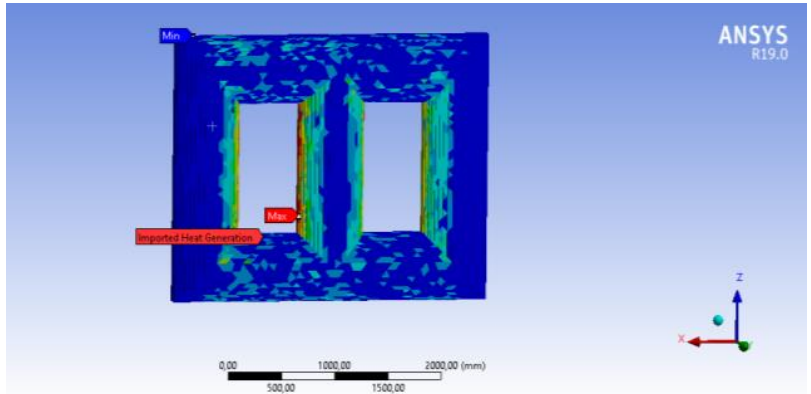

Şekil 7. Transformatörün 3D kritik

noktalardaki 1sı akışı 


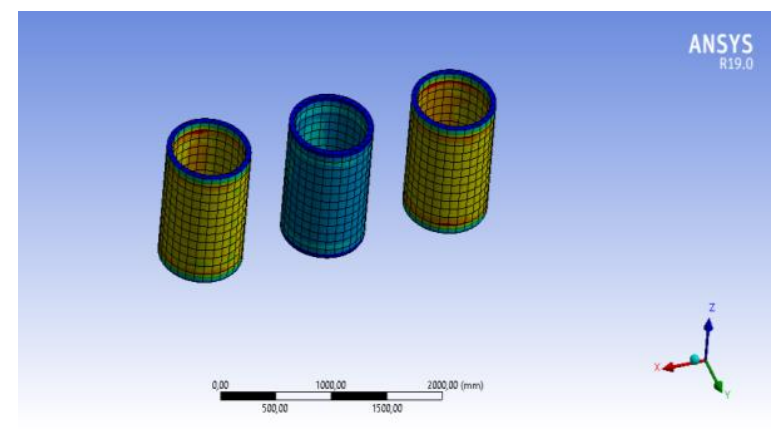

Şekil 8. Sargıların 3D 1Sı akışı

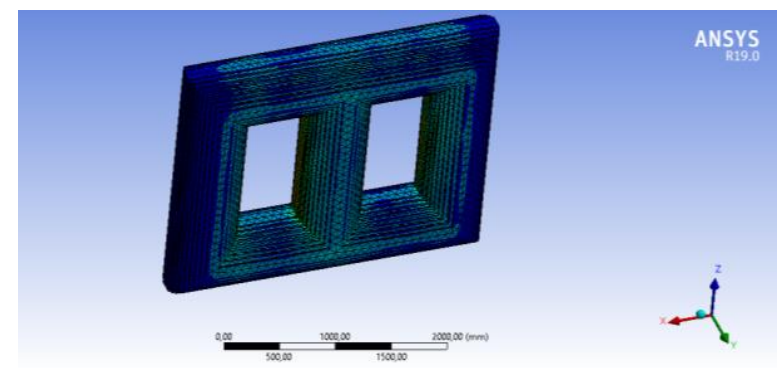

Şekil 9. Nüvenin 3D toplam 1sı akış1

Meydana gelen sicaklıklar sirasıyla; AG sargisinda $89.32{ }^{\circ} \mathrm{C}$ ve $88.71{ }^{\circ} \mathrm{C}, \mathrm{YG}$ sargisında $92.4{ }^{\circ} \mathrm{C}$ ve $91.01{ }^{\circ} \mathrm{C}$, Nüvede $88.3^{\circ} \mathrm{C}$ ve $84.78^{\circ} \mathrm{C}$ olarak ölçülmüştür. Bu şekillerde görüldüğü üzere, transformatördeki maksimum sıcaklık 92.4 ${ }^{\circ} \mathrm{C}$ ve $\mathrm{YG}$ sargısında olduğu belirlenmiştir. Transformatörün deneysel is1 testinde maksimum sicaklik $89.31^{\circ} \mathrm{C}$ olarak bulunmuştur. Simülasyon sonucu ile deneysel ölçüm sonuç arasındaki yaklaşık 3,09 ${ }^{\circ} \mathrm{C}$ olmuştur. $\mathrm{Bu}$ değer tasarlanan modelin doğruluk derecesini ortaya koymaktadır. Genel olarak sargiların olduğu yerler en sıcak yerlerdir. Çünkü bu bölgelerde trafonun aktif parçaları yer almaktadır. $\mathrm{Bu}$ nedenle dönüşen toplam kayıpların büyük bir kısmı bu bölgelerde meydana gelmektedir.

Nüvenin maksimum sicaklığ sargılarınkinden daha az olmuştur ve maksimum sıcaklık değeri nüvenin orta bacağında meydana gelmiştir. Bu sebeple nüvede meydana gelen kayılar sargılarda meydana gelen kayıplardan daha az olmuştur.

\section{Sonuçlar}

Tasarlanan termal model ile dağıtım trafosunun simülasyonu başarılı olmuştur. Sargıların yer aldığı bölgede maksimum sıcaklık ile pratik ölçümde elde edilen sıcaklık değeri karşılaştırıldığında yaklaşık olarak \% 2'lik fark meydana geldiği görülmüştür. Bu değer, transformatörün 1sıl alanının simülasyonunun gerçeğe çok yakın olduğunu ve trafo için modifikasyon ve performans iyileştirmede bir tasarım aracı olarak Sonlu Elemanlar Yönteminin kullanılabileceği anlamına gelmektedir.

\section{Kaynaklar}

Hjalmars, M. 2012. Optmiization, Study on Oil Flow and Temperature Distribution in Power Transformer Windings, MS.c. Thesis, Stockholm, sweden.

Yugendrao K. N. 2016. Structural Modeling of a Three Phase Core type Transformer using ANSYS Maxwell 3D, International Journal Of Innovative Research In Electrical, Electronics, Instrumentation And Control Engineering Vol. 4, Issue 4, April, pp. 17-20.

Kardag, R. 2012. Temperature Distribution in Power Trasformers, MS.c. Thesis, Electrical and Electronics Engineering in Middle East Technical University September.

OROSZ, T. KLEIZER, G. IVÁNCSY, T. Z. TAMUS, Á. 2016. Comparison of methodsforcalculation of core-form power transformer'score temperature rise, Periodica Poly technica Electrical 
Engineering and Computer Science, 60(2), pp. 88-95.

Myint, M. L. OO, Y. A. 2014. Analysis of distribution transformer design using FEA, International Journal of Scientific Research Engineering \&Technology (IJSRET), Volume 3, Issue 4, July (773-775)

Chen, Y. Pillay, P. 2002. An Improved Formula for Lamination Core Loss Calculation in Machine Operating with
High Frequency and High Flux Density Excitation, IEEE.

Madžarević, V. Kapetanović, I. Tešanović, Kasumović, M. M. 2011. Different Approach to Thermal Modeling of Transformers - a comparison of methods, INTERNATIONAL JOURNAL of ENERGY and ENVIRONMENT, Issue 5, Volume 5, p-610-617. 